\title{
FATIGUE AND MUSCLE FUNCTION IN PROSTATE CANCER SURVIVORS RECEIVING DIFFERENT TREATMENT REGIMENS
}

FADIGA E FUNÇÃO MUSCULAR EM SOBREVIVENTES DE CÂNCER DE PRÓSTATA EM DIFERENTES TRATAMENTOS

FATIGA Y FUNCIÓN MUSCULAREN SOBREVIVIENTES DE CÁNCERDEPRÓSTATA EN DIFERENTES TRATAMIENTOS

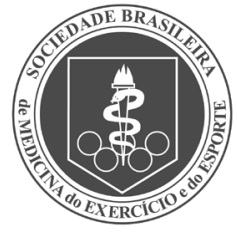

Original Article Artigo Original Artículo Original
Sandro Nobre Chaves 1,2

(Physical Education Professional)

Filipe Dinato de Lima $a^{3,4}$

(Physical Education Professional)

Martim Bottaro'

(Physical Education Professional)

Márcio Rabelo Mota ${ }^{4}$

(Physical Education Professional)

Ricardo Jacó de Oliveira'

(Physical Education Professional)

1. Universidade de Brasília, Faculdade de Educação Física, Brasília, DF, Brazil.

2. Faculdades Integradas (IESGO), Formosa, GO, Brazil.

3. Universidade de Brasília,

Faculdade de Ciências da Saúde,

Brasília, DF, Brazil.

4. Centro Universitário de Brasília, Faculdade de Ciências da Educação e da Saúde, Brasília, DF, Brazil.

\section{Correspondence:}

Filipe Dinato de Lima

Laboratório de Pesquisa em Treinamento de Força, Faculdade de Educação Física, Campus Universitário Darcy Ribeiro, Universidade de Brasília, Brasília, DF, Brazil. 70910-970.

fdinatolima@gmail.com

\begin{abstract}
Introduction: Prostate cancer is the most prevalent neoplastic disease in men. After diagnosis, different treatment regimens are proposed based on the stage of the cancer. These treatments affect physical and muscle function, quality of life, and prognosis differently. Objectives: To assess fatigue, muscle strength, muscle thickness, and muscle quality in prostate cancer survivors undergoing androgen deprivation therapy (ADT). Methods: Ten ADT patients, eight non-ADT patients and 18 healthy control subjects were enrolled in this study. Perceived fatigue was assessed through the 20-item Multidimensional Fatigue Inventory. Muscle thickness and quality (e.g., echo intensity) were assessed through B-mode ultrasound. Muscle strength and work capacity were assessed using an isokinetic dynamometer. The groups were compared with one-way ANOVA and Bonferroni adjustment. Results: Muscle thickness, peak torque, and work capacity were lower in ADT than in the control group (CON) $(p=0.021$; $p=0.005 ; p<0.001$, respectively). ADT showed greater echo intensity than CON $(p=0.005)$ and $N-A D T(p=0.046)$. There were no differences between N-ADT and CON in terms of muscle thickness, peak torque, work capacity, and echo intensity ( $p>0.05)$. General fatigue was greater in both ADT ( $p=0.030)$ and N-ADT ( $p=0.047)$ compared to CON. Physical fatigue was greater in ADT than CON $(p=0.006)$. Conclusion: ADT patients showed lower levels of muscle function and greater levels of perceived fatigue than healthy control subjects. It appears that muscle function remains lower in ADT patients, even several years after treatment initiation, although this does not apply to non-ADT patients. Level of evidence Il; Diagnostic Studies - Investigating a Diagnostic Test.
\end{abstract}

Keywords: Prostatic neoplasms; Fatigue; Muscle strength; Physical fitness.

\section{RESUMO}

Introdução: O câncer de próstataéa doença neoplásica mais frequentenos homens. Após seu diagnóstico, diferentes métodos de tratamento são propostos baseados no estágio do câncer. Esses tratamentos afetam diferentemente a função física e muscular, qualidade de vida e o prognóstico. Objetivos: Avaliar a fadiga, força muscular, espessura muscular e a qualidade muscular dos sobreviventes ao câncer de próstata que foram submetidos a terapia de privação androgênica (ADT). Métodos: Dez pacientes ADT, oito não ADT (N-ADT) e 18 indivíduos saudáveis no grupo controle (CON) foram inscritos neste estudo. A fadiga percebida foi avaliada através do Multidimensional Fatigue Inventory composto por 20 itens. A espessura e qualidade musculares (eco-intensidade) foram avaliadas através de um aparelho de ultrassom B-mode. A força muscular e a capacidade de trabalho foram avaliadas utilizando um dinamômetro isocinético. Os grupos foram comparados através de ANOVA de um fatore ajuste de Bonferroni. Resultados: O grupo ADT apresentou menor espessura muscular, pico de torque e capacidade de trabalho do que o grupo controle ( $p=0,021 ; p=0,005 ; p<0,001$, respectivamente). O grupo ADT demonstrou maior eco-intensidade que o grupo controle $(p=0,005)$ e N-ADT $(p=0,046)$. Não foram encontradas diferenças entre o grupo N-ADT e CON quanto à espessura muscular, pico de torque, capacidade de trabalho e eco-intensidade $(p>0,05)$. A fadiga geral foi maior tanto no grupo $A D T(p=0,030)$ quanto no grupo $N-A D T(p=0,047)$ quando comparada ao grupo CON. A fadiga física foi maior no grupo ADT do que no grupo CON $(p=0,006)$. Conclusão: Os pacientes submetidos à terapia de privação androgênica demonstraram menores níveis de função muscular emaiores niveis de fadiga percebida do que os indivíduos saudáveis do grupo controle. Parece que a função muscular permanece menor em pacientes submetidos à ADT vários anos após o início do tratamento, o que não ocorre com os pacientes N-ADT. Nível de evidência ll; Estudos diagnósticos - Investigação de um exame para diagnóstico.

Descritores: Neoplasias da próstata; Fadiga; Força muscular; Aptidão física.

\section{RESUMEN}

Introducción: El cáncer de próstata es la enfermedad neoplásica más frecuente en los hombres. Después de su diagnóstico, diferentes métodos de tratamiento son propuestos basados en la etapa del cáncer. Estos tratamientos afectan de forma diferente la función física y muscular, la calidad de vida y el pronóstico. Objetivos: Evaluar la fatiga, fuerza muscular, espesor muscular, y la calidad muscular de sobrevivientes al cáncer de próstata que fueron sometidos a la terapia de privación de andrógenos (ADT). Métodos: Diez pacientes ADT, ocho no ADT (N-ADT) y 18 individuos sanos en el grupo control (CON) fueron inscriptos en este estudio. La fatiga percibida fue evaluada a través del Multidimensional Fatigue Inventory compuesto por 20 items. El espesor y calidad muscular (eco intensidad) fueron evaluadas a través de un aparato de ultrasonido B-mode. La fuerza musculary la capacidad de trabajo fueron evaluadas en un dinamómetro isocinético. Los grupos fueron comparados a través de ANOVA de un factory ajuste de 
Bonferroni. Resultados: El grupo ADT demostró menor espesor muscular, pico de torque y capacidad de trabajo que el grupo control ( $p=0,021 ; p=0,005 ; p<0,001$, respectivamente). El grupo ADT demostró mayor eco intensidad que el grupo control $(p=0,005)$ y N-ADT $(p=0,046)$. No se encontraron diferencias entre el grupo N-ADT y el grupo CON, con respecto al espesor muscular, pico de torque, capacidad de trabajo y eco intensidad ( $p>0,05$ ). La fatiga general fue mayor tanto en el grupo ADT ( $p=0,030)$ como en el grupo N-ADT ( $p=0,047)$, cuando comparada al grupo CON. La fatiga física fue mayor en el grupo ADT que en el grupo CON $(p=0,006)$. Conclusión: Los pacientes sometidos a la terapia de privación de andrógenos demostraron menores niveles de función muscular y mayores niveles de fatiga percibida que los individuos saludables del grupo control. Parece que la función muscular permanece menor en pacientes sometidos a ADT varios años después del inicio del tratamiento, lo que no ocurre con los pacientes N-ADT. Nivel de evidencia ll; Estudios de diagnóstico - Investigación de un examen de diagnóstico.

\section{Descriptores: Neoplasias de la próstata; Fatiga; Fuerza muscular; Aptitud Física.}

\section{INTRODUCTION}

Prostate cancer (PC) is classified as a global burden issue by the World Health Organization, since it is the most prevalent neoplastic disease in men. ${ }^{1}$ Only in United States, PC is responsible for $20 \%$ of new cancer diagnoses in men. ${ }^{2}$ The rises in PC's incidence is related to population ageing and to the exposure to risk factors, such as unhealthy lifestyles. ${ }^{3}$ Although aging could be considered the main risk factor, lifestyle and ethnicity also affects PC's incidence. ${ }^{3,4}$

After diagnosis, several interventions could be applied to treat PC. The most prevalent treatment regimens in early stages of $\mathrm{PC}$ are radiotherapy, radical prostatectomy, or the combination between them. ${ }^{5,6}$ However, in progressive stages of PC, androgen deprivation therapy (ADT) is widely used in order to reduce testosterone levels and attenuate PC's progression, leading to fall in $90 \%$ of prostatic specific antigen.

Although all regimens of treatment aim to defeat PC, they could affect distinctly quality of life and physical function. ${ }^{7}$ Therefore, both cancer and therapy could induce late side effects directly related to severity of such therapy and disease. ${ }^{5,8} \mathrm{PC}$ survivors submitted to radiotherapy and radical prostatectomy usually report urinary dysfunction, sexual impotence, and intestinal disorders. ${ }^{9}$ Otherwise, PC survivors submitted to ADT could report cardiovascular impairments, depression, anemia, osteoporosis, and loss of muscle tissue. Recent studies showed the effect of ADT after only three months of treatment, leading to lower strength and functionality, and greater fatigue than non-ADT PC survivors. ${ }^{10}$ Furthermore, long-term ADT could deteriorate physical function and increase the risk of cardiovascular disease, insulin resistance and metabolic syndrome. ${ }^{11,12}$

Considering that both incidence and survivorship are rising due to aging population, unhealthy habits and screening improvement, the growing population of survivors requires specialized follow-up and care. ${ }^{13}$ Only two studies have examined physical functions in PC survivors submitted do ADT and non-ADT. ${ }^{10}$ However, both studies only assessed survivors up to 12 months after the treatment beginning. Also, both studies used non-gold standard field tests to assess muscle function. Therefore, it is mandatory to understand the effects of different regimens of treatment for prostate cancer in order to provide a better long-term care and to clarify the magnitude of late side effects, even several years after the beginning of therapy. So, the purpose of the present study was to assess muscle strength, muscle thickness and muscle quality in prostate cancer survivors submitted to androgen deprivation therapy. Therefore, prostate cancer survivors submitted to ADT were compared to prostate cancer survivors submitted to non-ADT and to control healthy subjects.

\section{METHODS}

\section{Subjects}

All participants were volunteers recruited from community, by word of mouth and advertisements on Internet. Prostate cancer survivors were also recruited from public and private local hospitals. The participants were informed of the purpose, procedures and risks of the study prior to signing an informed consent. The procedures were approved by the University Institutional Review Board. Ten PC survivors were included in ADT group, eight PC survivors that undergone non-ADT therapies, such as radical prostatectomy and/or radiotherapy, were included in N-ADT group, and eighteen control healthy subjects matched by age were included in control group (CON). Patients were included in ADT and N-ADT groups if they were diagnosed with non-metastatic prostate cancer through a prostate biopsy. Additionally, participants included in ADT group must have been performing androgen deprivation therapy for at least 12 months. Healthy control subjects included in CON were selected based on similar age and absence of cancer diagnosis. Participants were excluded of this study if they were diagnosed with hypertension, cardiovascular, metabolic and/or neuroendocrine disease, and/or had any orthopedic limitation. All procedures performed in this study were in accordance with the ethical standards of the institutional and/or national research ethical committee (CAAE: 94882218.8.0000.0023) and with the 1964 Helsinki declaration and its later amendments or comparable ethical standards. Informed consent was obtained from all individual participants included in the study.

\section{Experimental procedures}

After signing the informed consent form, the participants reported to the Strength Training Research Laboratory for testing. All groups performed the following tests and evaluations in the same sequence: 1) self-perceived fatigue, 2) anthropometrics measurements, 3) muscle thickness and echo intensity, and 4) strength and work capacity. All evaluations were performed at the same period of the day (afternoon), by the same researcher, in a controlled temperature room, from January to April 2018. All participants were asked to follow pre-assessment guidelines before reporting to the laboratory including: avoid physical exertion for at least 48 hours prior to the evaluations.

\section{Self-perceived fatigue}

Self-perceived fatigue was measured through MFI-20. This questionnaire was designed to asses' different levels of fatigue between different subjects, groups and/or different conditions, as well as various populations. Several dimensions comprise the questionnaire, which measure fatigue experienced in previous days. In this study, general fatigue and physical fatigue were used as markers of self-perceived fatigue.

\section{Muscle thickness and quality}

Muscle thickness (MT) was measured using B-mode ultrasound (Philips, VMI, Brazil). A 7.5-MHz scanning probe was placed on the skin perpendicular to the tissue interface. The scanning probe was coated with a water-soluble transmission gel to provide acoustic contact without 
depressing the dermal surface. No additional pressure was applied to standardize the compression on the dermal surface. Before measurement, all volunteers rested for 10 minutes in order to guarantee the rest condition and to avoid the influence of any body fluids disordered by walking. The MT images were determined in lower-body muscles including the rectus femoris and vastus intermedius. The measurement was taken at $60 \%$ of the distance from the greater trochanter to the lateral epicondyle and $3 \mathrm{~cm}$ lateral to the midline of the anterior thigh. Once the examiner found a satisfactory image, it was frozen, stored and analyzed using the software Image-J (National Institute of Health, USA, version 1.49). The distance between subcutaneous adipose tissue-rectus femoris interface and vastus intermedius-bone interface was designated as MT. All measurements and analyses were performed three times by the same researcher and the mean value was used for analysis.

Muscle quality was assessed by echo intensity (El). The El was determined by gray-scale analysis using the standard histogram function Image-J. In order to assess El in the rectus femoris, a region of interest was selected in muscle without any bone or surrounding fascia, with a depth limit of 5 $\mathrm{cm}$. When this setting was insufficient to display the entire muscle, only the superficial part was used for analysis. A reliable measurement of $\mathrm{El}$ is extracted from a minimum of 15\% of muscle area. ${ }^{14}$ The El was expressed in values between 0 (black) and 256 (white). The increase in El value represents a decrease in muscle quality. In our laboratory, the ultrasound intra-rater reliability was 0.94 and the coefficient of variation was $2.4 \%$.

\section{Peak torque and work capacity}

Isokinetic muscle strength (peak torque (PT)) and work capacity (WC) was measured using an isokinetic Biodex System 3 (Biodex Medical, Inc., Shirley NY, USA) dynamometer. Subjects were positioned on the dynamometer seat with safety belts fastened to the trunk, pelvis and thigh to avoid extraneous body movements. The lateral epicondyle of the femur was used to align the knee rotation axis and the dynamometer rotation axis, allowing free knee extension and flexion from $85^{\circ}$ flexion to full extension. Gravity correction was obtained by measuring the torque exerted by the lever arm and the participant's leg at $30^{\circ}$ flexion as well as in a relaxed position. The values of the isokinetic variables were automatically adjusted for gravity with the software Biodex Advantage (Biodex Medical, Inc., Shirley NY, USA). The calibration of dynamometer was carried out according to the specifications provided by the manufacture. For the test, participants were asked to cross their arms across the chest. The same researcher carried out the test procedures for all participants and provided verbal encouragement.

As part of warm-up and familiarization with isokinetic knee extension and warm-up, subjects performed one set of 10 submaximal knee isokinetic extension at $120^{\circ} . \mathrm{s}^{-1}$. Two minutes after familiarization/warm-up session, volunteers performed two sets of four maximal isokinetic knee extension at $60 \% \mathrm{~s} .{ }^{15}$ The greatest torque achieved in both sets was considered (PT). WC was also measured on the right knee extensors. Three minutes after strength protocol, volunteers performed 30 maximal isokinetic knee extensions at 120\%/s for WC evaluation. Work capacity was calculated as the amount of torque produced throughout the entire range of motion of all repetitions. Test-retest reliability coefficient (ICC) value for knee extensor peak torque was 0.91 in our laboratory.

\section{Statistical Analysis}

Data are presented as mean \pm standard deviation. Normal distribution parameters were checked with Shapiro-Wilk test. To compare anthropometric characteristics, muscle strength, muscle quality and perceived fatigue between all groups, one-way analyses of variance were used. The Bonferroni adjustment was applied as post-hoc analysis. The Statistical Package for Social Sciences (SPSS), version 21.0 (IBM, USA) was used for all analyses. The alpha level was set at $5 \%(p \leq 0.05)$.

\section{RESULTS}

Ten PC survivors composed ADT group, eight PC survivors composed N-ADT group, and 18 apparently healthy men composed CON group. ADT and N-ADT clinical characteristics are reported in Table 1.

Descriptive and comparative data analysis of ADT, N-ADT and CON are reported in Table 2 . No significant differences in any physical characteristics between ADT, N-ADT and CON were observed ( $p>0.05$ ).

Muscle function, muscle quality and fatigue variables are presented in Figure 1. The one-way analyses of variance showed a significant effect between groups on muscle thickness ( $F=4.158 ; p=0.025)$, peak torque $(F=5.983 ; p=0.006)$, work capacity $(F=9.529 ; p=0.001)$, echo

Table 1. Clinical Characteristics of ADT and N-ADT, expressed as mean \pm SD.

\begin{tabular}{c|c|c}
\hline Clinical Characteristics & ADT $(\mathbf{n}=10)$ & N-ADT $(\mathbf{n}=\mathbf{8})$ \\
\hline Sessions of CT & $3.90 \pm 1.29$ & 0 \\
\hline Sessions of RT & $2.50 \pm 4.08$ & $4.63 \pm 4.69$ \\
\hline Years from treatment begins & $5.10 \pm 3.12$ & $5.60 \pm 3.53$ \\
\hline Age at diagnosis & $69.80 \pm 5.57$ & $64.75 \pm 4.58$ \\
\hline
\end{tabular}

CT: chemotherapy; RT: radiotherapy; ADT: androgen deprivation therapy group; N-ADT: non-androgen deprivation therapy.

Table 2. Descriptive and comparative data of all groups, expressed in mean \pm standard deviation.

\begin{tabular}{c|c|c|c}
\hline Variable & ADT $(\mathbf{n}=10)$ & N-ADT $(\mathbf{n}=\mathbf{0 8})$ & CON $(\mathbf{n}=\mathbf{1 8})$ \\
\hline Age (years) & $74.40 \pm 5.76$ & $69.75 \pm 5.92$ & $72.17 \pm 6.54$ \\
\hline Weight $(\mathrm{kg})$ & $77.44 \pm 14.75$ & $82.25 \pm 9.20$ & $77.94 \pm 9.47$ \\
\hline Height $(\mathrm{m})$ & $1.63 \pm 0.07$ & $1.70 \pm 0.07$ & $1.69 \pm 0.07$ \\
\hline BMl $\left(\mathrm{kg} \cdot \mathrm{m}^{-2}\right)$ & $28.87 \pm 4.42$ & $28.68 \pm 3.41$ & $27.40 \pm 2.91$ \\
\hline
\end{tabular}

ADT: androgen deprivation therapy group; N-ADT: non-androgen deprivation therapy; CON: control group; BMI body mass index.

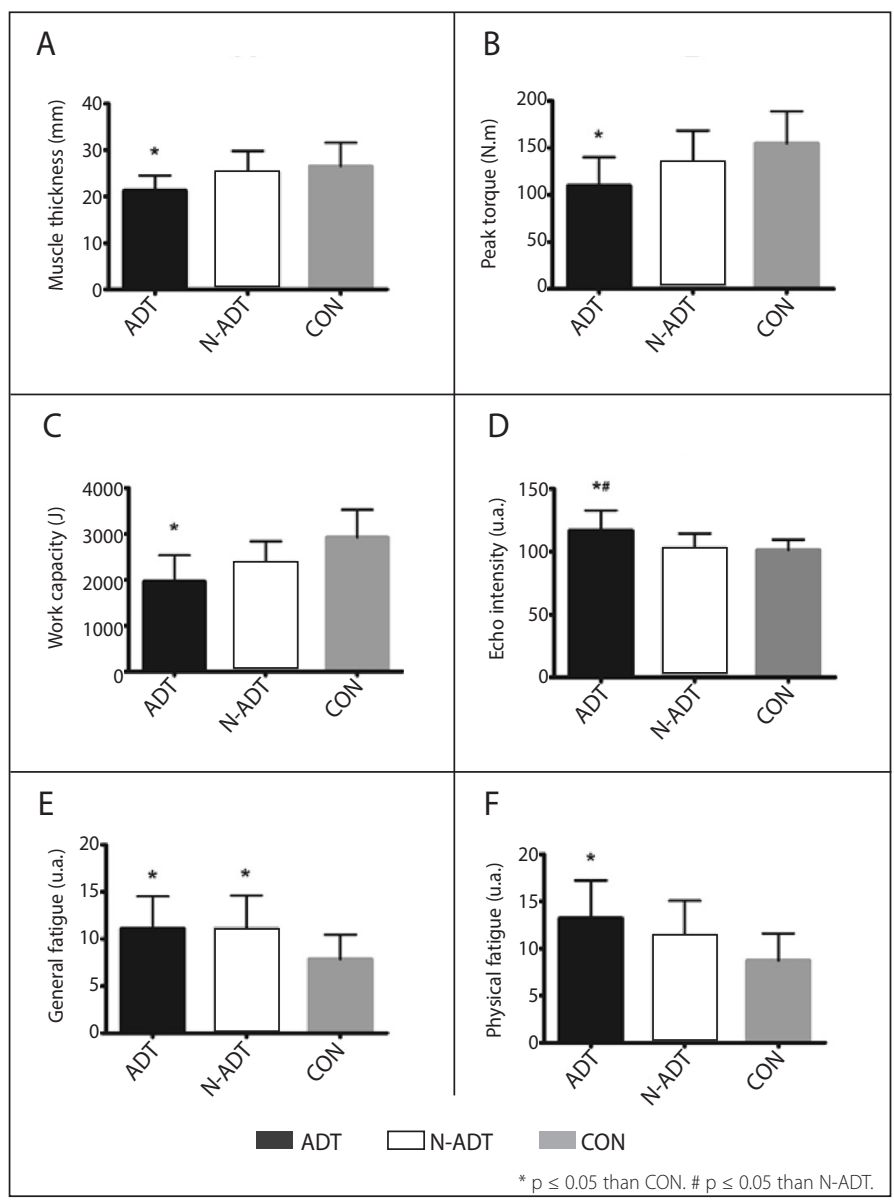

Figura 1. Variables of muscle function and fatigue in ADT, N-ADT and CON. (A) muscle thickness, (B) peak torque, (C) work capacity, (D) echo intensity, (E) general fatigue, (F) physical fatigue. 
intensity ( $F=6.192 ; p=0.005)$, general fatigue $(F=5.244 ; p=0.011)$, and physical fatigue $(F=5.880 ; p=0.007$ ). ADT group showed lower muscle thickness, peak torque, and work capacity than CON ( $p=0.021$; $p=0.005 ; p<0.001$, respectively). ADT showed greater echo intensity than CON ( $p=0.005)$ and N-ADT ( $p=0.046)$. There were no differences between N-ADT and CON on muscle thickness, peak torque, work capacity, and echo intensity ( $p>0.05)$. General fatigue was greater in both ADT $(p=0.030)$ and N-ADT $(p=0.047)$ compared to CON. Physical fatigue was greater in ADT than CON ( $p=0.006)$. There was no difference between $\mathrm{N}$-ADT and CON on physical fatigue $(p=0.797)$.

\section{DISCUSSION}

The purpose of the present study was to assess muscle strength, thickness and quality in prostate cancer survivors submitted to androgen deprivation therapy, and to compare ADT patients to non-ADT patients and control healthy subjects. Therefore, the main results suggest that ADT patients showed lower muscle thickness and function, and greater perceived fatigue than control healthy subjects. Also, non-ADT prostate cancer survivors showed greater general fatigue than control healthy subjects, despite no differences in muscle function between them.

Testosterone inhibition in PC patients could affect skeletal muscle tissue due to upregulation of myostatin, imbalance between muscle protein breakdown and synthesis, and attenuation of hypertrophic pathways Akt/mTOR/P70S6K. ${ }^{16,17}$ Moreover, mitochondrial dysfunction induced by both disease and treatment could affect skeletal muscle tissue due to reductions in AMPK and PGC1-a expression, and reactive oxygen species overproduction. ${ }^{18}$ In this study PC patients submitted to ADT showed lower muscle thickness than CON, while no difference was observed between non-ADT patients and CON. Likewise, Chang et al. (2014) ${ }^{19}$ showed a substantial reduction in muscle tissue of PC survivors after 20 week of testosterone deprivation. Indeed, such reduction could last for several years after the treatment beginning, as suggested in this study.

Regarding muscle strength, ADT patients showed lower peak torque than CON, while no difference was observed between non-ADT patients and CON. Considering that muscle strength is directly related to muscle tissue amount, ${ }^{16}$ the lower peak torque in ADT compared to CON could be explained by the lower muscle thickness. Moreover, physiological dysfunctions induced by both treatment and disease, such as Warburg effect, acidosis and oxidative stress, could also reduce muscle strength. 20,21 Therefore, several studies have already showed lower muscle strength in ADT patients compared to CON.22 However, this study showed that muscle strength remains lower in ADT patients compared to healthy subjects even several years after the treatment beginning.

Furthermore, physiological impairments induced by both cancer and treatment could also affect the ability of the muscle tissue to perform multiple repetitions or prolonged tasks, exposing fatigue objectively. Falls in work capacity occurs due to reduced glycogen content and impaired glucose transport in response to insulin. ${ }^{23}$ Cancer survivors may show an increased systemic acidity due to Warburg effect and overproduction of hydrogen ions, ${ }^{24}$ which affect glycogen's production and content. Otherwise, insulin sensibility could also affect glucose transportation and work capacity. The inflammatory imbalance in cancer survivors could play a role in insulin resistance, since an increased pro-inflammatory cytokines release reduces insulin sensibility. ${ }^{25}$ Furthermore, insulin resistance is a well-established adverse effect of ADT, induced by gonadotropin-releasing hormone agonists. ${ }^{26}$ Therefore, it is not unexpected that PC survivors submitted to ADT show lower work capacity, even several years after the treatment beginning.
Echo intensity is frequently used as an indicator of muscle quality because it represents the accumulation of intramuscular adipose and connective tissue. A decreased muscle quality has already been reported in diseases such as chronic obstructive pulmonary disease and diabetes. ${ }^{27}$ However, in cancer survivors, de Lima FD, et al. (2018) ${ }^{15}$ showed no differences between physically active Hodgkin's lymphoma survivors and healthy subjects matched by age and gender. Apparently, active Hodgkin's lymphoma survivors recover their muscle characteristics and functions after treatment, and time since treatment completion seems to affect positively muscle function in Hodgkin's disease. ${ }^{15}$ In our study, PC survivors submitted to ADT showed worse muscle quality than both non-ADT patients and control healthy subjects, even several years after the treatment beginning. Such phenomenon could be justified by imbalance between protein breakdown and synthesis, 16,17 and metabolic dysfunctions. ${ }^{26}$

Another interesting finding of this study is the greater general fatigue reported by both ADT and non-ADT PC survivors, while only ADT patients showed a greater physical fatigue compared to control healthy subjects. An increased general fatigue is widely reported in cancer survivors and has been already described in several cancer types. ${ }^{28,29}$ According O'Higgins, et al. (2018) ${ }^{30}$ a cascade of biochemical, physiological, and psychological dysregulation of important biological systems contribute to cancer-related fatigue. Actually, a greater general fatigue is reported by cancer survivors even when muscle functions are preserved, ${ }^{15}$ suggesting that disease may play a role in general fatigue more than treatment.

Otherwise, only ADT patients showed greater physical fatigue than control healthy subjects. The physical fatigue assessed in Multidimensional Fatigue Inventory 20-item is related to the perception of physical exhaustion and could be indeed related to muscle characteristics and functions. Consequently, the increased physical fatigue in ADT patients is explained by the worse muscle strength, muscle thickness, muscle quality and work capacity compared to control healthy subjects.

This cross-sectional study was not without limitations. An important limitation was the small size of the sample. Evidently, these statements above are simply speculations at this time and more research is needed to confirm or refute these possibilities. However, this study should be seen as a hypothesis-generating study, providing initial information about fatigue mechanisms and muscle function in prostate cancer survivors even several years after the treatment beginning. Also, to the best of our knowledge, this is the first study that applied both subjective and objective markers of fatigue together. For future research, it is recommended that a larger sample size and other cancer types be included.

\section{CONCLUSION}

In summary, a lower level of muscle function and a higher level of self-perceived fatigue were observed in prostate cancer survivors submitted to androgen deprivation therapy compared to control healthy subjects with matched age. It appears that muscle function remains lower in ADT patients even several years after the treatment beginning, which does not occur with non-ADT patients, since no differences were observed in muscle function between non-ADT patients and control healthy subjects. Further investigations are required to clarify if strategies, such as exercise, can attenuate or even reverse these debilitating side effects of androgen deprivation therapy.

All authors declare no potential conflict of interest related to this article 
AUTHORS' CONTRIBUTIONS: Each author made significant individual contributions to this manuscript. SNC (0000-0002-9450-7747)*: Substantial contribution in the conception of the study, writing, revision, and final approval of the version of the manuscript to be published; FDL (0000-0001-5748-7540)*: Substantial contribution in the conception of the study, data analysis, writing, revision, and final approval of the version of the manuscript to be published; MB (0000-0002-4315-3176)*: writing, revision, and intellectual concept; MRM (0000-0003-0881-305X)*: data analysis and writing; RJO (0000-0003-3052-5783)*: writing and revision. *ORCID (Open Researcher and Contributor ID).

\section{REFERENCES}

1. Packer JR, Maitland NJ. The molecular and cellular origin of human prostate cancer. Biochim Biophys Acta. 2016;1863(6 Pt A):1238-1260.

2. Siegel RL, Miller KD, Jemal A. Cancer Statistics, 2017. CA Cancer J Clin. 2017;67(1):7-30.

3. Singh SD, Henley SJ, Ryerson AB. Surveillance for Cancer Incidence and Mortality - United States, 2012. MMWR Morb Mortal Wkly Rep. 2016;63(55):17-58.

4. Siegel RL, Miller KD, Jemal A. Cancer statistics, 2018. CA Cancer J Clin. 2018;68(1):7-30.

5. Litwin MS, Tan HJ. The Diagnosis and Treatment of Prostate Cancer: A Review. Jama. 2017;317(24):2532-2542.

6. Tilki D, Pompe RS, Bandini M, et al. Local treatment for metastatic prostate cancer: A systematic review. Int J Urol. 2018;25(5):390-403.

7. Cuypers M, Lamers RED, Cornel EB, van de Poll-Franse LV, de Vries M, Kil PJM. The impact of prostate cancer diagnosis and treatment decision-making on health-related quality of life before treatment onset. Support Care Cancer. 2018;26(4):1297-1304.

8. Kgatle MM, Kalla AA, Islam MM, Sathekge M, Moorad R. Prostate Cancer: Epigenetic Alterations, Risk Factors, and Therapy. Prostate Cancer. 2016;2016:5653862.

9. Lamers RE, Cuypers M, de Vries M, van de Poll-Franse LV, Ruud Bosch JL, Kil PJ. How do patients choose between active surveillance, radical prostatectomy, and radiotherapy? The effect of a preference-sensitive decision aid on treatment decision making for localized prostate cancer. Urol Oncol. 2017;35(2):37.e39-37.e17.

10. Gonzalez BD, Jim HSL, Small BJ, et al. Changes in physical functioning and muscle strength in men receiving androgen deprivation therapy for prostate cancer: a controlled comparison. Support Care Cancer. 2016;24(5):2201-2207.

11. Focht BC, Lucas AR, Grainger E, et al. Effects of a Group-Mediated Exercise and Dietary Intervention in the Treatment of Prostate Cancer Patients Undergoing Androgen Deprivation Therapy: Results From the IDEA-P Trial. Ann Behav Med. 2018;52(5):412-428.

12. Gallagher EJ, LeRoith D. Obesity and Diabetes: The Increased Risk of Cancer and Cancer-Related Mortality. Physiol Rev. 2015;95(3):727-748.

13. Stewart B, Wild CP. World cancer report 2014. World Health Organization. 2016

14. Caresio C, Molinari F, Emanuel G, Minetto MA. Muscle echo intensity: reliability and conditioning factors. Clin Physiol Funct Imaging. 2015;35(5):393-403.

15. de Lima FD, Bottaro M, de Oliveira Valeriano R, et al. Cancer-Related Fatigue and Muscle Quality in Hodgkin's Lymphoma Survivors. Integr Cancer Ther. 2018;17(2):299-305.
16. Cheung AS, Zajac JD, Grossmann M. Muscle and bone effects of androgen deprivation therapy: current and emerging therapies. Endocr Relat Cancer. 2014;21(5):R371-394.

17. Nilsen TS, Thorsen L, Fossa SD, et al. Effects of strength training on muscle cellular outcomes in prostate cancer patients on androgen deprivation therapy. Scand J Med Sci Sports. 2016;26(9):1026-1035.

18. Carson JA, Hardee JP, VanderVeen BN. The emerging role of skeletal muscle oxidative metabolism as a biological target and cellular regulator of cancer-induced muscle wasting. Semin Cell Dev Biol. 2016;54:53-67.

19. Chang D, Joseph DJ, Ebert MA, et al. Effect of androgen deprivation therapy on muscle attenuation in men with prostate cancer. J Med Imaging Radiat Oncol. 2014;58(2):223-228.

20. Wang XS, Woodruff JF. Cancer-related and treatment-related fatigue. Gynecol Oncol. 2015;136(3):446-452

21. Wang XS, Zhao F, Fisch MJ, et al. Prevalence and characteristics of moderate-to-severe fatigue: a multicenter study in cancer patients and survivors. Cancer. 2014;120(3):425-432.

22. Galvao DA, Taaffe DR, Spry N, et al. Enhancing active surveillance of prostate cancer: the potential of exercise medicine. Nat Rev Urol. 2016;13(5):258-265.

23. Ferreira DV, Gentil P, Ferreira-Junior JB, Soares SRS, Brown LE, Bottaro M. Dissociated time course between peak torque and total work recovery following bench press training in resistance trained men. Physiol Behav. 2017;179:143-147.

24. Swietach P, Vaughan-Jones RD, Harris AL, Hulikova A. The chemistry, physiology and pathology of pH in cancer. Philos Trans R Soc Lond B Biol Sci. 2014;369(1638):20130099.

25. Paulsen G, Mikkelsen UR, RaastadT, Peake JM. Leucocytes, cytokines and satellite cells: what role do they play in muscle damage and regeneration following eccentric exercise? Exerc Immuno/ Rev. 2012;18:42-97.

26. Choi SM, Kam SC. Metabolic effects of androgen deprivation therapy. Korean J Urol. 2015;56(1):12-18

27. Robles PG, Sussman MS, Naraghi A, et al. Intramuscular Fat Infiltration Contributes to Impaired Muscle Function in COPD. Med Sci Sports Exerc. 2015;47(7):1334-1341.

28. Saligan LN, Olson K, Filler K, et al. The biology of cancer-related fatigue: a review of the literature. Support Care Cancer. 2015;23(8):2461-2478.

29. Sha F, Zhuang S, Zhou L, et al. Biomarkers for cancer-related fatigue and adverse reactions to chemotherapy in lung cancer patients. Mol Clin Oncol. 2015;3(1):163-166.

30. O'Higgins CM, Brady B, O'Connor B, Walsh D, Reilly RB. The pathophysiology of cancer-related fatigue: current controversies. Support Care Cancer. 2018;26(10):3353-3364. 